\title{
DECISIVE INFLUENCE OF ENAMEL SURFACE LAYER ON CORROSION RESISTANCE AND DEGRADATION OF HUMAN TEETH ENAMEL IN WHITE WINE
}

\author{
\#D. GALUSKOVÁ*, P. GAALOVÁ*, D. GALUSEK*, J. KOVÁČ**, D. KOVÁČ** \\ *Joint Glass Centre of the IIC SAS, TnUAD, and FChFT STU, Študentská 2, 91150 Trenčin, Slovak Republic \\ **Department of Stomatology and Maxillofacial Surgery, Faculty of Medicine, Comenius University, \\ Heydukova 10, 81250 Bratislava, Slovak Republic \\ ${ }^{\#}$ E-mail: dagmar.galuskova@tnuni.sk
}

Submitted February 15, 2017; accepted April 10, 2017

\begin{abstract}
Keywords: Degradation, Enamel, Acidic wine solution, Microstructure
To evaluate enamel degradation in white wine at simulated body temperatures $\left(25,37^{\circ} \mathrm{C}\right)$ and the influence of the acidic corrosive agent on the natural enamel surface as well as on the surface where the upper layer of natural enamel was removed by polishing. The content of major ( $\mathrm{Ca}, \mathrm{P}, \mathrm{Mg}, \mathrm{K}, \mathrm{Na}$ ), and minor ( $\mathrm{Al}, \mathrm{Cu}, \mathrm{Fe}, \mathrm{Mn}, \mathrm{Zn}$ ) components in the corrosion solution of white wine, and chemical composition of enamel were determined by atomic emission spectrometry in inductively coupled plasma (ICP AES). The chemical resistance of enamel in wine was monitored through determination of major components of enamel, i.e. calcium and phosphorus leached to the corrosion solution, combined with detailed study of corroded surfaces by SEM. The initial rates of corrosion per hour were calculated by linear curve fitting under quasi-dynamic conditions. Time dependences of normalized leaching values of phosphorus and calcium $n l(P)$ and $n l(C a)$ in the initial time period of the corrosion test are comparable, which refers to congruent dissolution of hydroxyapatite as the main component of natural teeth in the initial 3 hours period of the corrosion test. Demineralization of the enamel exposed to white wine at temperatures $25^{\circ} \mathrm{C}$ and $37^{\circ} \mathrm{C}$ in the initial time period is gradually reversed through re-mineralisation from calcium saturated corrosion solution. Removal of the approximately $1 \mathrm{~mm}$ thick surface layer of the enamel by polishing results in fivefold increase of the initial dissolution rates of enamel in white wine.

Upper, approximately $\sim 1 \mathrm{~mm}$ thick, enamel layer has a substantial influence on the chemical durability of human teeth in white wine solution.
\end{abstract}

\section{INTRODUCTION}

Any food or substance with a critical $\mathrm{pH}$ value of less than 5.5 (chewable vitamins, $\mathrm{C}$ tablets, aspirin tablets or powders, alcohol) can demineralize teeth. In this respect, a significant attention has been paid to carbonated soft drinks, such as Coca Cola, and various non-carbonated drinks, including fruit juices, as a major component of many diets, and their wide spread consumptions by whole population including adolescents and small children. Since the year 2000 the corrosive potential of acidic drinks has been broadly discussed in numerous scientific papers [1-6]. In vitro and in situ corrosion models were applied for evaluating tooth substance loss $[7,8]$. The investigations were focused also to wear and friction behaviour of enamel in acidic environments as well as the evaluation of mechanical properties of corroded and un-corroded enamel by nanoindentation and microhardness measurements $[3,4,9]$. However, the results provided in these works are questionable: hardness and microhardness is always determined by indentation (either Vickers hardness testing or nanoindentation) on corroded surfaces where the upper layer of enamel was removed by polishing prior to corrosion/degradation to provide a flat substrate for mechanical testing. The surface layer of enamel is known to contain higher concentrations of fluorides and lower concentrations of magnesium and carbonates than the enamel bulk, thus providing higher corrosion resistance and better protection against caries and cavity formation [10]. Subsurface parts of enamel are then exposed, which are known to be more sensitive to caries formation, once the surface is penetrated by a corrosive agent [11]. Corrosion and degradation tests of human enamel reported in the literature (e.g. the work of Shellis et al. [7] and the references cited therein) also often differ in the conditions of polishing procedure, resulting in removal of surface layers of enamel, often of un-controlled thickness, exposed tested surface area, volume of the applied corrosive solution and the time of exposure. Such studies then overestimate the influence of acidic attack on demineralization and micromechanical properties of intact human teeth enamel.

Testing of the degradation behaviour of natural enamel is also complicated by the diversity of human teeth themselves, their origin, age and the environment to which they are exposed. It is not possible to specify a single test capable of covering all situations. 
Standardization of the in vitro and in situ models often used for evaluating tooth substance loss is difficult to implement due to several variables that affect the extent of erosion/degradation [7, 8]. The citric and acetic acids or saturated acidic beverages prevail as the corrosion environment in the published papers describing kinetics of the enamel dissolution $[4,6,12,13]$.

The acid corrosion caused by alcoholic beverages, including wine, is reported less frequently, mainly due to the fact that the degradation by wine is not observed so often, and only applies for relatively narrow population groups, such as wine growers and tasters. Wine derives its acidity mostly from the fruit-acid content, especially tartaric and malic acid, and from smaller concentrations of citric and succinic acids. Their corrosive potential is therefore lower than in the drinks with high concentrations of citric acid, and the dental degradation in wine is therefore a long-term process most frequently appearing in the case studies of wine tasters, winemakers or judges [14-18]. The available data generally indicate that the corrosion potential of white wine is higher than in red varieties, due to the fact that longer maturation periods required for red wines may result in the greater production of potential inhibitors of enamel degradation. $[16,18]$.

The extent of enamel degradation in wines is mostly monitored by the microscopy techniques (optical or scanning electron microscopy), relying mostly on evaluation of degradation related morphology changes of tested surfaces, followed by complementary measurement of surface composition with various analytical microscopy techniques, such as energy dispersive X-ray spectroscopy (EDX). Obtaining the information from the analysis of corrosion solution is in the case of wine corrosion less frequent, often due to related experimental difficulties. Wine in particular is considered, from the analytical point of view, as complex and difficult matrix for the elemental analysis, mainly due to natural content of $\mathrm{Ca}$ and $\mathrm{P}$, as the major components released in the course of enamel demineralization, and the content of other minor elements. In this work we therefore put the emphasis on the development of a method, which would facilitate the analysis of specific elements, and $\mathrm{P}$ in particular, released from enamel into solution. Quasi-dynamic conditions of testing have been applied in order to collect data for evaluation of the kinetics of enamel chemical dissolution in white wine. The amounts of dissolved calcium and phosphorus (re-calculated to phosphates), and normalized to the weight fraction of the respective elements in the enamel facilitated comparison of the corrosion tests at different temperatures, and proposal of the corrosion mechanism. The influence of the acidic corrosive agent on the natural enamel surface as well as the surface where the upper layer of natural enamel was removed by polishing is also discussed. The temperatures $\left(25-37^{\circ} \mathrm{C}\right)$ and the volume of the corrosion solution (4 - $5 \mathrm{ml}$ ) were selected in order to be consistent with conditions reflecting extensive wine tasting [14-16].

The main goal of the presented work is to apply the optimized testing and analytical procedures for evaluation of the corrosion resistance of human tooth enamel in-vitro both at original intact surfaces, and at the surfaces where approximately $1 \mathrm{~mm}$ thick layer of the enamel was removed by polishing, simulating the preparation of enamel surface for mechanical testing by Vickers indentation or nanoindentation. The extent of degradation has been studied in a complex way, by combination of quasi-dynamic testing conditions, and the use of small amount of corrosive agent approximating the amount of wine, which is in contact with teeth during real consumption, with chemical analysis of corrosion media and examination of degraded surface by SEM. An analytical method for determination of $P$ content in wine matrix by ICP AES has been also developed and verified. This approach was expected to yield the answers to the following questions:

- Is there any substantial difference between the corrosion resistance of the original intact surface of tooth enamel and the subsurface region?

- Are the results of corrosion tests published in literature $[$ e.g. 15, 16] and carried out on polished surfaces relevant also for intact enamel?

- Can the removal of the surface enamel layer (e.g. in caries) accelerate further damage of teeth by diet-related corrosion?

\section{EXPERIMENTAL}

\section{Materials and methods}

Decontamination of intact caries-free human molars and premolars extracted due to orthodontic reasons (in total 91 specimens of teeth were tested originating from individuals of either gender and various age) $[15,16,18]$ was performed by immersing the teeth into $3 \%$ hydrogen peroxide solution for $5 \mathrm{~s}$ in order to minimize the risk of transmission of blood-borne pathogens [19], and stored in deionized water at the temperature of $\sim 5^{\circ} \mathrm{C}[16,18]$. Each tooth specimen was embedded in polymeric resin (Demotec) and positioned so that the lateral bulge side was exposed. Two sets of samples were prepared. The first series had the lateral bulge side exposed above the level of the filler. The teeth from the second group were fully embedded in the resin and then mechanically polished to remove approximately $1 \mathrm{~mm}$ thick surface layer of the enamel. Smooth surface was achieved by additional vibration polishing with $0.1 \mu \mathrm{m}$ diamond suspension (Figure 1a). A care was taken to perform the polishing in the way, which would facilitate the exposure of inner part of the enamel, without exposing underlying dentine layers. The area of the exposed surface was measured from 
the microscopic photographs with the use of the image analysis software Lucia 4.72 (LIM, Ltd. Prague, Czech Republic) used with the optical microscope (Nikon Eclipse ME600). Undulating surface of the natural teeth enamel exhibits numerous scratches, micro-cracks and abrasion sites (Figure 1b) comparing to smooth profile of the polished specimens (Figure 1a).

The specimens were then cleaned in de-ionized water for 15 min using ultrasonic bath and then exposed to the white wine (Pinot blanc, year 2011) $(\mathrm{pH}=3.392$ \pm 0.003 measured at $24^{\circ} \mathrm{C}$ ) produced in Modra wine region in the south-western part of the Slovak Republic. Three parallel specimens were exposed to the wine solution at the same time. $100 \mu \mathrm{l}$ of the corrosive liquid was spread so as to fully cover the exposed surface of the enamel. The tests were carried out at two different temperatures: the body temperature of $37^{\circ} \mathrm{C}$ and the room temperature of $25^{\circ} \mathrm{C}$. The temperature variation was maintained within $\pm 1^{\circ} \mathrm{C}$ in the climatic chamber (Angelantoni Discovery DY110) at $90 \%$ relative humidity. High relative humidity was applied in order to prevent evaporation of the corrosion liquid from specimen's surface. The enamel surface lesions are clinically referring to the cumulative fluid exposures [16]. In this work the cumulative effect was achieved by applying the quasi-dynamic conditions of the tests, i.e. the specified volume of the corrosion solution was replaced with the fresh one in the time interval of 30 minutes up to the maximum duration of the corrosion test $6 \mathrm{~h}$. Sampled corrosive solutions were diluted to 5 $\mathrm{ml}$ with $2 \% \mathrm{HNO}_{3}(\mathrm{pH} \sim 2)$ in order to stabilize dissolved calcium and phosphate ions. The blank experiments were simultaneously carried out with the same volume of the corrosion solution at the polished surface of the polymeric resin in order to check (and if necessary subtract) the amounts of the element leached from the resin.

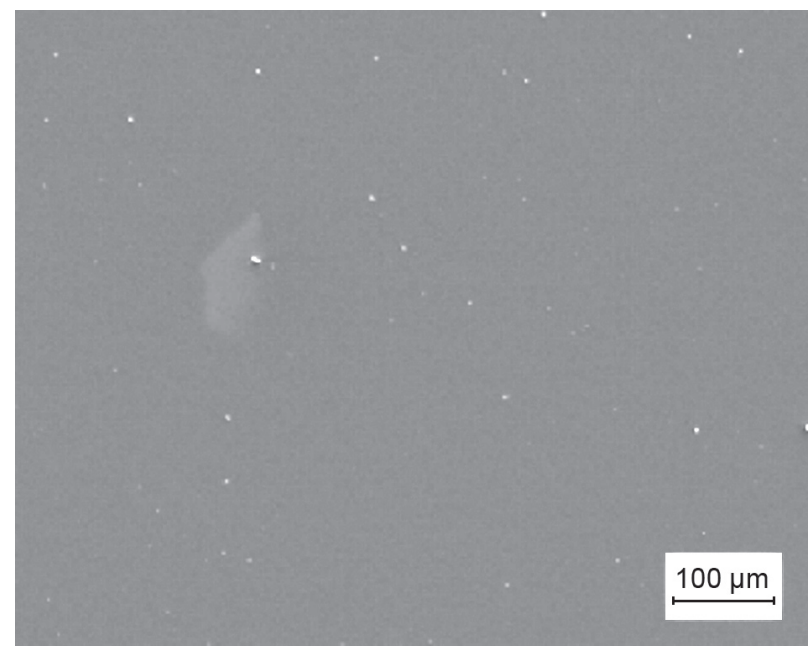

a)
The X-ray powder diffraction (Panalytical Empyrean) was applied to identify the phase composition of the enamel specimens. Microwave digestion (Berghof Speedwave 4) was applied in order to dissolve the enamel powder specimens $(0.05 \mathrm{~g})$ with the aid of the mixture of mineral acids: $65 \% \mathrm{HNO}_{3}(6 \mathrm{ml}), 36 \% \mathrm{HCl}$ $(2.5 \mathrm{ml})$ and $40 \% \mathrm{HF}(1 \mathrm{ml})$ for the chemical analysis. The elemental analysis of the liquid specimens was carried out with the optical emission spectrometer with inductively coupled plasma (ICP OES, Vista MPX, Varian). Due to high content of organic acids, various anions (including phosphates), and trace metallic elements, wines represent a difficult matrix for chemical analysis by spectroscopic techniques. This had to be accounted for and the applied analytical techniques had to be optimized and verified from the point of view of its repeatability and reproducibility. Also, there exist no commercially available certified reference materials, which could be used for verification of the contents of metallic elements and phosphorus in wines determined by spectroscopic techniques. For that reason a certified reference material has been prepared in house, with the matrix similar to white wines, according to the procedure described by López-Artiquez et al. [20]. The details on the developed analytical techniques, including the selection of spectral lines used for determination of individual metallic elements (particularly $\mathrm{Ca}, \mathrm{Cu}$, $\mathrm{Na}, \mathrm{K}, \mathrm{Zn}, \mathrm{Mn}, \mathrm{Fe}, \mathrm{Mg}$ ) and $\mathrm{P}$, the limits of detection and quantifications are in detail described in [21]. The repeatability and reproducibility of phosphorus determination by ICP OES was verified by alternative $P$ determination by spectrophotometry with ammonium molybdate, described in $[22,23]$. The repeatability of determination of the contents of individual elements leached from enamel was evaluated from measurement of at least 10 parallel samples. The relative standard deviations of determination of $\mathrm{Ca}$ and $\mathrm{P}$ were $2.1 \%$,

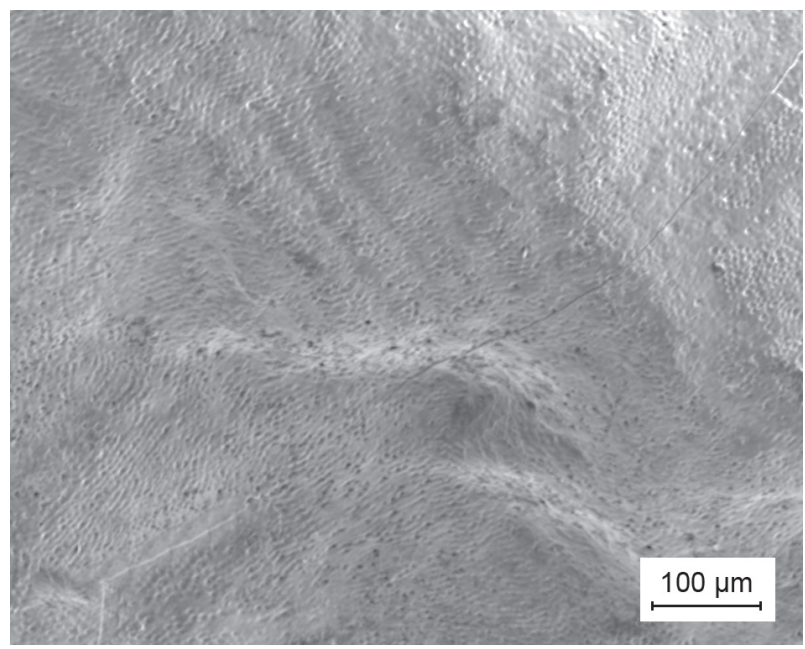

b)

Figure 1. SEM micrographs of enamel after removal of $\sim 1 \mathrm{~mm}$ thick layer by polishing (a), and a natural surface of a human tooth (b). 
and $0.5 \%$, respectively. The reproducibility of the measurement was determined from the analysis of the same sample under identical conditions in three consecutive days. The relative standard deviations for reproducibility measurements were $2.8 \%$ and $3.0 \%$ for $\mathrm{Ca}$ and $\mathrm{P}$, respectively. Statistical analyses of the amounts of $\mathrm{Ca}$ and $\mathrm{P}$ released into the corrosion medium was carried out, and the results are given as the means \pm SDs of at least 3 parallel measurements of samples corroded under the same conditions (duration of exposure, temperature). A univariate analysis of variance was used to investigate differences in $\mathrm{Ca}$ and $\mathrm{P}$ release from polished and un-polished specimens, and the significance level was set at $\mathrm{P}<0.05$. Detailed microstructural analysis was performed on the corroded specimen surfaces using the scanning electron microscope (SEM, JEOL 7600-F).

\section{RESULTS AND DISCUSSION}

Hydroxyapatite is the main inorganic component both of bones and teeth [24, 25]. The XRD powder diffraction analysis of the un-corroded enamel sample confirmed the presence of hydroxyapatite as the only detectable crystalline phase. The XRD pattern of the un-corroded enamel is shown in the Figure 2a. Regarding the dissolution of apatites, eight models have been already proposed in the available literature to simulate the processes involved. Each model described in detail in [26], was found to have some limitations and drawbacks. According to the chemical model, initial stages of apatite dissolution consist of calcium detachment from the surface and incorporation of protons instead. In acidic solutions proton(s), chemisorb on the nearest phosphate group. Prevailing positive charge then causes detachment of the nearest calcium cations. Removing of each calcium cation results in a decrease of attraction

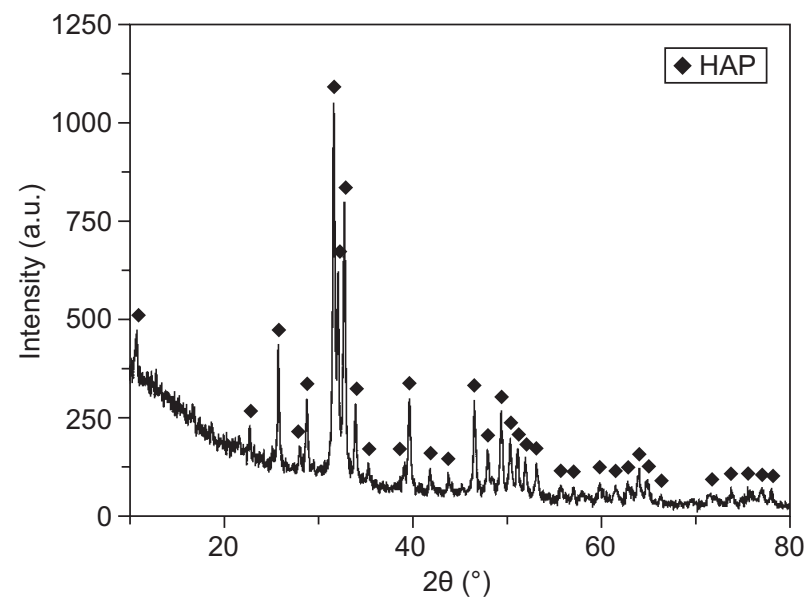

a) forces between the nearest (to this calcium cation) phosphate group and the rest of the apatite crystals. When all or almost all neighbouring $\mathrm{Ca}^{2+}$ ions have been removed, phosphate anion(s) ( such as $\mathrm{HPO}_{4}{ }^{2-}$ or $\mathrm{H}_{2} \mathrm{PO}_{4}{ }^{-}$) also detach from the surface [26]. Such model would result in preferential detachment of calcium in the initial time period of apatite dissolution, and only subsequent release of phosphate ions into the solution.

Our results show that the white wine applied under the specified quasi-dynamic conditions caused extensive corrosion both of the intact and of polished enamel, in accord with published data, which report demineralization of the enamel (depletion of the enamel surface with respect to calcium and phosphorus) to the depth of up to $60 \mu \mathrm{m}$ [16]. The elemental analysis of the corrosion solutions was focused on determination of calcium and phosphorus, since the content of minor components, such as $\mathrm{Al}, \mathrm{Na}, \mathrm{Mg}$, and $\mathrm{Zn}$, possibly leached into the corrosive solutions from the enamel, would be overlapped by the matrix of the white wine (Table 1).

The concentration-time dependences were obtained from the cumulative amounts $n l_{i}^{t}(\mathrm{mg})$ of $\mathrm{Ca}$ and $\mathrm{P}\left(\mathrm{mg} \mathrm{l}^{-1}\right)$ normalized with respect to the weight fraction of the particular element in enamel, $w_{i}$, and an average area $S$ exposed to corrosive solution (Equation 1). The average area of exposed surface $(S)$ determined by image analysis was $23.7 \pm 4.4 \mathrm{~mm}^{2}$. In all tests the ratio in the equation (1) between the exposed surface area $S$ and the volume of corrosion liquid was held within the range $1.9-2.8 \mathrm{~cm}^{-1}$.

$$
n l_{i}^{t}=\frac{\left(c_{i}-c_{b l}\right)}{w_{i} \cdot S / V}+n l_{i}^{t-\Delta t}
$$

The weight fraction of $\mathrm{Ca}$ and $\mathrm{P}$ in the enamel was determined by chemical analysis by ICP OES of the enamel dissolved in the mixture of inorganic acids

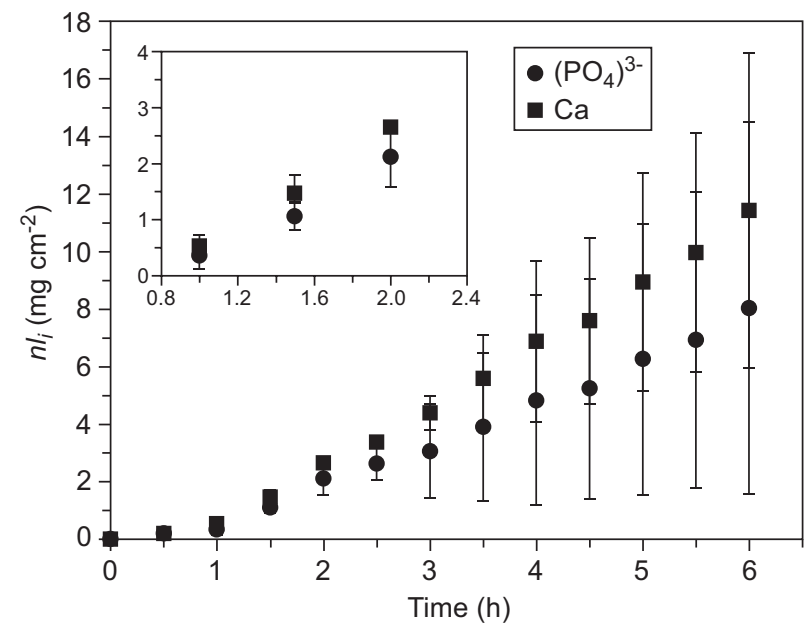

b)

Figure 2. X-ray diffraction pattern of un-corroded enamel (a) and time dependences of the $\mathrm{nl}_{\mathrm{i}}$ values calculated for natural (unpolished) enamel exposed for $6 \mathrm{~h}$ to white wine at $25^{\circ} \mathrm{C}$. The inset of the image (b) shows the plot of the initial time interval of enamel dissolution. 
Galusková D., Gaalová P., Galusek D., Kováč J., Kováč D.

Table 1. Comparison of the ICP OES elemental analysis of the white wine solution and of a sample of tested enamel.

\begin{tabular}{|c|c|c|c|c|c|c|c|c|c|c|c|}
\hline & & $\mathrm{Ca}$ & $\mathrm{P}$ & $\mathrm{Mg}$ & $\mathrm{K}$ & $\mathrm{Na}$ & $\mathrm{Al}$ & $\mathrm{Cu}$ & $\mathrm{Fe}$ & $\mathrm{Mn}$ & $\mathrm{Zn}$ \\
\hline \multirow{2}{*}{ wine solution } & wt. $\%\left(\times 10^{-4}\right)$ & 77.5 & 221 & 81.7 & 645 & 25.7 & 0.85 & 0.82 & 2.47 & 1.57 & 1.2 \\
\hline & $s$ & 2.8 & 6 & 1.4 & 6 & 2.4 & 0.05 & 0.02 & 0.05 & 0.01 & 0.1 \\
\hline \multirow{2}{*}{ Enamel } & wt. \% & 29.5 & 17.1 & $<0.1$ & & & $<0.1$ & & & & $<0.1$ \\
\hline & $s$ & 2.5 & 0.7 & & & & & & & & \\
\hline
\end{tabular}

wt. $\%$-weight percentage, $s$-standard deviation

with the use of the microwave assisted decomposition technique (for details see the section 2 Materials and methods). The amount of phosphorus was recalculated to $\mathrm{PO}_{4}{ }^{3-}$ and compared to the amount of calcium. The concentrations $\left(c_{i}\right)$ of phosphorus and calcium in the corrosion solution were corrected with respect to the results of the blank tests $\left(c_{\mathrm{bl}}\right)$, carried out under the same conditions.

The mean $n l_{i}$ values were obtained from three tooth specimens measured in parallel. Time dependences of the $n l_{i}$ values calculated for natural (unpolished) enamel exposed to white wine at $25^{\circ} \mathrm{C}$ are plotted in Figure $2 \mathrm{~b}$. The standard deviation of the amounts of $\mathrm{Ca}$ and $\mathrm{PO}_{4}{ }^{3-}$ measured in the solution varied with time and the mean $n l_{i}$ values of calcium tend to be slightly higher than the $n l_{i}$ of the phosphate anions. In this case irregularities of surface area exposed to the wine solution caused the increase of standard deviations of measured concentrations of dissolved species or solution chemistry became favourable for precipitation of the phosphate phases. The cumulative approach in calculation of the $n l_{\mathrm{i}}$ values needs to be also considered, with possible unidirectional accumulation of the experimental errors. Overlap of the time dependences of the initial normalized leaching values $n l_{i}^{t}$ of the phosphate anions, $n l\left(\mathrm{PO}_{4}{ }^{3-}\right)$, and calcium, $n l(\mathrm{Ca})$ refers, in contrary to the data from chemical models described in [26], to congruent dissolution of hydroxyapatite as the main mineral component of natural teeth enamel in the initial time period of the corrosion test (Figure 2b). However, in comparison to the phosphate ions, calcium seems to dissolve slightly faster after the initial $2 \mathrm{~h}$ period of the test (Figure 2b, inset).

The specimens with mechanically polished enamel surface, resulting in removal of the natural surface enamel layer, were tested under the same conditions. The time dependencies of $n l_{i}(\mathrm{Ca})$ and $n l_{i}\left(\mathrm{PO}_{4}\right)$ values for the initial time interval are plotted in the Figure 3, showing linear increase with time, and confirming the congruent dissolution of the apatite components in the wine solution. Unlike the tests with the natural enamel surface the amounts of dissolved calcium and phosphate ions from the polished surface are more than five times higher. The initial rates $8.74 \pm 0.22 \mathrm{mg} \cdot \mathrm{cm}^{-2} \cdot \mathrm{h}^{-1}$ and $1.69 \pm 0.06 \mathrm{mg} \cdot \mathrm{cm}^{-2} \cdot \mathrm{h}^{-1}$ were calculated from the linear slopes of dissolution curves for polished and natural enamel surfaces in the time interval between 0 and $3 \mathrm{~h}$ from the measured amounts of leached $\mathrm{Ca}$, respectively (Figure 3). Decreasing chemical durability might be then related to the removal of the upper, more corrosion resistant surface layer of the enamel. The previously published data on corrosion resistance of human tooth enamel obtained from polished surfaces $[15,16]$ most likely underestimate its corrosion resistance with respect to the results discussed above. Damage of the surface enamel layer (e.g. by caries, abrasion or abfraction) exposes less corrosion resistant interior of enamel layer, increasing the risk of further corrosion damage. In [16] the authors investigated the influence of exposure to 50 white and 50 red European wines with different $\mathrm{pH}$ values and different titration acidities on Ca release from polished enamel, with no specification of the thickness of removed enamel layer. The results vary broadly, with the white wines conferring statistically more significant corrosion damage than the red ones. For the white wines the amount of leached $\mathrm{Ca}$ after $6 \mathrm{~h}$ exposure ranged between 2.87 and $12.37 \mathrm{mg} \cdot \mathrm{dl}^{-1}$ of $\mathrm{Ca}$ released from $25 \mathrm{~mm}^{2}$ of the exposed surface. After re-calculation to square unit, these results are comparable to those obtained in the present paper for leaching of $\mathrm{Ca}$ from the teeth with the upper enamel layer removed by polishing.

The idea about the significant influence of the surface layer on the corrosion resistance of tooth enamel is supported by the published data on dissolution of stoichiometric hydroxyapatite in various solutions with the

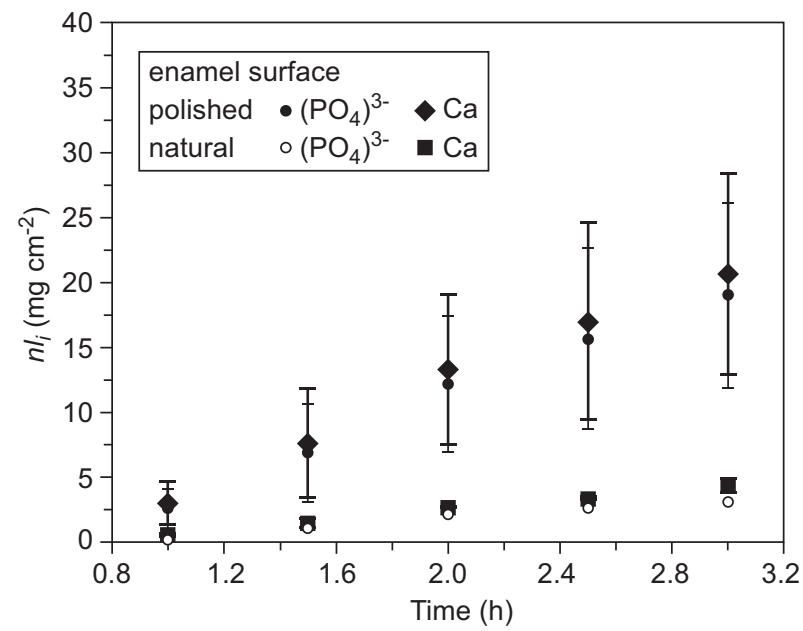

Figure 3. The time dependencies of $n l_{i}(\mathrm{Ca})$ and $n l_{i}\left(\mathrm{PO}_{4}\right)$ values in the initial $(3 \mathrm{~h})$ period of corrosion leached from both the natural and polished enamel surface. 
$\mathrm{pH}$ values ranging between 4.90 and 9.94. The authors report that after removal of the so called "irreversible" surface, which generated excessive $\mathrm{Ca}$ and phosphate solution concentrations, the behaviour of apatite was reproducible [16, 27, 28]. Congruent/incongruent dissolution was based on the direct measurement of either the ionic concentrations in a solution or surface composition of apatite during dissolution. According to the definition, ions present in a solid may be dissolved simultaneously with dissolution rates proportional to their molar concentrations or non-simultaneously with different values of the dissolution rates for each ion (incongruent dissolution) [26]. Such congruent dissolution was observed also in this work for the initial time period up to $3 \mathrm{~h}$ for both test temperatures independently of the surface pretreatment (Figures 2b, 3). Negative deviation after $3 \mathrm{~h}$ of exposure (Figure $2 b$ ) was attributed to re-precipitation of HAP due to supersaturation of corrosion solution with respect to $\mathrm{Ca}^{2+}$ ions as will be in more detail discussed below. Moreover, presence of simple alkaline $\left(\mathrm{Na}^{+}, \mathrm{K}^{+}\right.$, $\mathrm{Ca}^{2+}$ ) base inorganic salts in solution can also have an influence on the equilibrium concentrations of phosphate and calcium ions released from apatite. Thus, whether apatite is dissolved congruently or incongruently might also depend on its initial chemical composition [26].

The natural enamel surface was significantly affected after $6 \mathrm{~h}$ exposure in wine at quasi-dynamic conditions. Two different regions could be distinguished at the corroded surface: either the internal parts of the apatite rods were completely etched away, with the surface layer of the rods sharply pointed out (Figure 4a) or the surface was recovered and the ends of the hydroxyapatite rods were covered with a solid phase of hydroxyapatite composition, re-precipitated from the solution (Figure 4b). Demineralization of the enamel exposed to wine

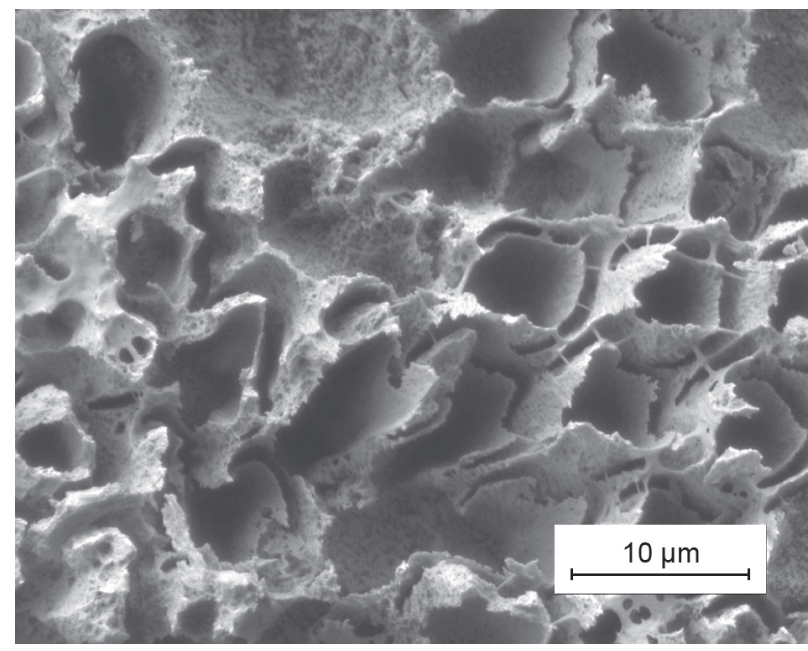

a) (even at the temperature as low as $25^{\circ} \mathrm{C}$, Figure $2 \mathrm{~b}$ ) in the initial time period can be thus gradually reversed through remineralisation from the corrosion solution saturated with respect to calcium in the latter stages of the corrosion test.

Chemical transformation of the enamel surface was observed also for the corrosion tests performed at $37^{\circ} \mathrm{C}$ (Figure 5). The corroded surface was completely covered with a new crystalline phase in the form of elongated crystallites. The original shape of the hydroxyapatite rods can be still distinguished after chemical corrosion of the surface. The internal part of the rods corroded in the initial time period of 3 hours was gradually refilled with the new crystalline apatite phase.

The dissolution curves constructed in the time interval between 3 and 6 hours differ depending on the temperature (Figure 6). For the corrosion test performed at $37^{\circ} \mathrm{C}$ the slope of the linear part of the curve is lower

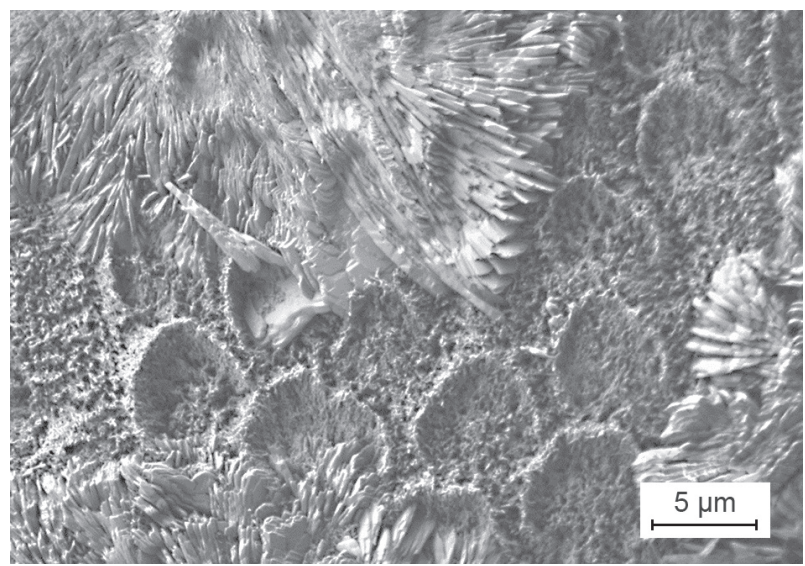

Figure 5. The enamel surface corroded at $37^{\circ} \mathrm{C}$ covered with a new crystalline phase in the form of elongated crystallites.

Figure 4. SEM micrographs of corroded enamel: an area with the internal parts of HAP rods completely etched away (a), and a surface where the ends of the hydroxyapatite rods were covered with a solid phase of hydroxyapatite composition, re-precipitated from the solution (b). 
than at $25^{\circ} \mathrm{C}$, with slight concentration de-acceleration of the ions transferred to the solution in the final stage of the test. At this stage any proposal of the mechanism becomes vague unless we know the exact surface area exposed to the corrosion fluid. The surface areas of polished specimens exposed to the corrosion solution $\left(23.7 \pm 4.4 \mathrm{~mm}^{2}\right)$ were therefore included into the calculation (Equation 1) and the normalized $n l$ values of $\mathrm{Ca}$ and $\mathrm{PO}_{4}{ }^{3-}$ were plotted as the function of time (Figure 7). This way, the elimination of the concentration deviations was achieved: for both temperatures the normalised amount of leached $\mathrm{Ca}$ and $\mathrm{PO}_{4}{ }^{3-}$ linearly increased with time. The slopes of the dissolution curves determined as a linear fit of all measured data in the whole time interval between 0 and $6 \mathrm{~h}$ were at $37^{\circ} \mathrm{C}$ $\left(2.07 \pm 0.07 \mathrm{mg} \cdot \mathrm{cm}^{-2} \cdot \mathrm{h}^{-1}\right)$ three times lower than at $25^{\circ} \mathrm{C}$ $\left(7.35 \pm 0.16 \mathrm{mg} \cdot \mathrm{cm}^{-2} \cdot \mathrm{h}^{-1}\right)$. This indicates that the chemical dissolution of enamel was hindered as soon as the equilibrium between the surface hydroxyapatite and the

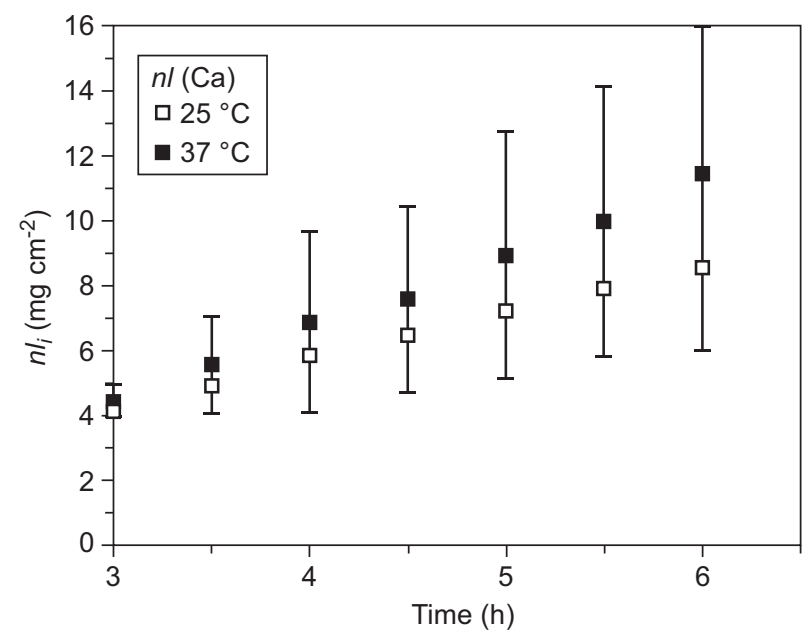

Figure 6. The dissolution curves plotted for natural enamel specimens in the time interval between 3 and 6 hours for corrosion at 25 and $37^{\circ} \mathrm{C}$.

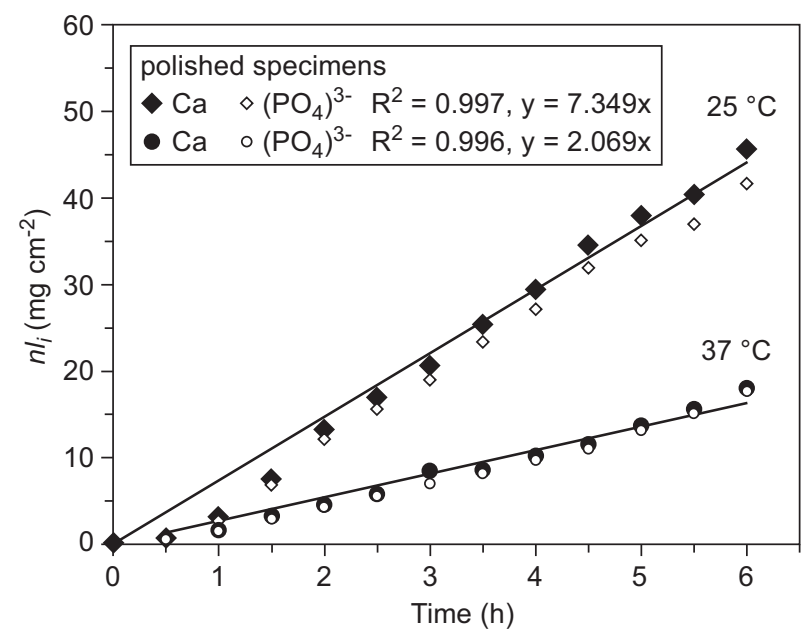

Figure 7. The normalized $\mathrm{nl}$ values of $\mathrm{Ca}$ and $\mathrm{PO}_{4}{ }^{3-}$ plotted as the function of time at 25 and $37^{\circ} \mathrm{C}$. solution has been achieved, followed with concentration decline of dissolved calcium and phosphate ions. In the final period of the corrosion tests at $25^{\circ} \mathrm{C}$, the amount of phosphate ions was slightly lower comparing to calcium, and the increase of standard deviations of the measured values was recorded. Depending on the area exposed to the acidic environment, this might be related to depletion of calcium and phosphate ions from the solution due to precipitation reaction and formation of the new apatite crystalline phase partially covering the corroded enamel surface (Figure 4).

A model with a self-inhibition layer formation describes formation of a calcium-rich layer on the surface of apatite during dissolution [29]. According to this model, apatite is dissolved by ionic detachment of calcium and phosphate ions from surface to a solution, the latter resulting in formation of a semi-permeable ionic membrane, a calcium-rich layer. Incongruent dissolution observed in the latter stages of the corrosion tests in this work can be thus attributed to the formation of a calcium-rich layer [26]. For a solution initially strongly undersaturated with respect to calcium, the attainment of the pseudo-steady state resulting in formation of calcium-rich layer can take a very long time. Unlike for other acidic solutions, wine itself contains significant amount of dissolved calcium and phosphate ions: the equilibrium with respect to dissolution of apatite from enamel can be therefore achieved in a relatively short period of time. A surface layer is then formed (Figures $4,5)$ with a chemical composition very likely different from that of the original hydroxyapatite of the enamel body. Such nonstoichiometric/stoichiometric dissolution at the nano and macro level was discussed by Dorozhkin [27]. The newly created surface layer can likely consist of either various calcium phosphates or the octacalcium phosphate.

\section{CONCLUSION}

In this work we studied in-vitro degradation of human teeth enamel in white wine at simulated body temperatures $\left(25,37^{\circ} \mathrm{C}\right)$. Degradation process was studied both on intact enamel, and enamel with surface layer removed by polishing. The extent of degradation was monitored through the amount of $\mathrm{Ca}$ and $\mathrm{P}$ leached into the solution, combined with detailed examination of degraded surface by SEM. The obtained results can be summarized as follows:

- Substantial influence of removal of upper, approximately $\sim 1 \mathrm{~mm}$ thick, enamel layer on the chemical durability of human teeth in white wine solutions was observed, resulting in the increase of the initial rate of enamel dissolution in white wine from $1.69 \pm 0.06 \mathrm{mg} \cdot \mathrm{cm}^{2} \cdot \mathrm{h}^{-1}$ in intact enamel to $8.74 \pm 0.22 \mathrm{mg} \cdot \mathrm{cm}^{2} \cdot \mathrm{h}^{-1}$ on polished surfaces. The amounts of $\mathrm{Ca}$ leached from polished enamel in this 
work are comparable to those obtained by other authors [e.g. 16] for leaching of $\mathrm{Ca}$ from the teeth with the upper enamel layer removed by polishing. The results suggest that removal of corrosion resistant surface layer might result in significant overestimation of the negative impact of acidic media on corrosion resistance of human tooth enamel.

- Based on the experimental data, especially the overlap of the initial values of $n l(\mathrm{Ca})$ and $n l\left(\mathrm{PO}_{4}{ }^{3-}\right)$, it is concluded that, in contrary to the data from chemical models described in [26], hydroxyapatite in the human teeth enamel dissolves congruently when exposed to corrosive action of the white wine, as a result of high $\mathrm{Ca}$ and $\mathrm{P}$ contents naturally occurring in the white wine. This contributes to formation of a layer of reaction products on enamel surface as a result of saturation of corrosion solution with respect to calcium and phosphate ions. Progressive recovery of the corroded inner parts of hydroxyapatite rods is observed.

\section{Acknowledgement}

The financial support of this work by the grant APVV 0218-11, and by the VEGA grant 2/0058/14 is gratefully acknowledged. The publication was created in the frame of the project "Centre of excellence for ceramics, glass and silicate materials", ITMS code 26220120056, based on the Operation Program Research and Development funded from the European Regional Development Fund.

\section{REFERENCES}

1. Finke M., Jandt K. D., Parker D. M. (2000): The early stages of native enamel dissolution studied with atomic force microscopy. Journal of Colloid and Interface Science, 232, 156-164. doi:10.1006/jcis.2000.7200

2. White A. J., Yorath C., ten Hengel V., Leary S. D., Huysmans M.-C. D., Barbour M. E. (2010): Human and bovine enamel erosion under 'single-drink'conditions. European Journal of Oral Sciences, 118, 604-609. doi:10.1111/j.1600-0722. 2010.00779.x

3. Lippert F., Parker D. M. Jandt K. D. (2004): In vitro demineralization/remineralization cycles at human tooth enamel surfaces investigated by AFM and nanoindentation. Journal of Colloid and Interface Science, 280, 442-448. doi:10.1016/j.jcis.2004.08.016

4. Barbour M. E., Parker D. M., Jandt K. D. (2003): Human enamel dissolution in citric acid as a function of $\mathrm{pH}$ in the range $2.30<-\mathrm{pH}<-6.30$ - a nanoindentation study. European Journal of Oral Science, 111, 258-262. doi:10.1034/j.16000722.2003.00039.x

5. Grippo J. O., Simring M., Schreiner S. (2004): Attrition, abrasion, corrosion and abfraction revisited. Journal of American Dental Association, 135, 1109-1118. doi:10.14219/ jada.archive. 2004.0369

6. Johansson A.-K., Sorvari R., Birkhed D., Meurman J. H. (2001): Dental erosion in deciduous teeth-an in vivo and in vitro study. Journal of Dentistry, 29, 333-340. doi:10.1016/ S0300-5712(01)00029-X

7. Shellis R. P., Ganss C., Ren Y., Zero D. T., Lussi A. (2011): Methodology and models in erosion research: Discussion and conclusions. Caries Research, 45, 69-77. doi:10.1159/000325971

8. West N. X., Davies M., Amaechi B. T. (2011): In vitro and in situ Erosion Models for Evaluating Tooth Substance Loss. Caries Research, 45, 43-52. doi:10.1159/000325945

9. Barbour M. E., Parker D. M., Jandt K. D. (2003): Enamel dissolution as a function of solution degree of saturation with respect to hydroxyapatite: a nanoindentation study. Journal of Colloid and Interface Science, 265, 9-14. doi:10.1016/S0021-9797(03)00087-0

10. Barbour M. E., Rees J. S. (2004): The laboratory assessment of enamel erosion: a review, Journal of Dentistry, 32, 591-602. doi:10.1016/j.jdent.2004.05.001

11. West N.X., Joiner A. (2014): Enamel mineral loss. Journal of Denistry, 42, S2-S11. doi:10.1016/S0300-5712(14) 50002-4

12. Barbour M. E., Parker D. M., Allen G. C., Jandt K. D. (2005): Human enamel erosion in constant composition citric acid solutions as a function of degree of saturation with respect to hydroxyapatite. Journal of Oral Rehabilitation, 32, 16-21. doi:10.1111/j.1365-2842.2004.01365.x

13. Barbour M. E., Finke M., Parker D. M., Hughes J. A., Allen G. C., Addy M. (2006): The relationship between enamel softening and erosion caused by soft drinks at a range of temperatures. Journal of Dentistry, 34, 207-213. doi:10.1016/j.jdent.2005.06.002

14. Gray A., Ferguson M. M., Wall J. G. (1998): Wine tasting and dental erosion. Case report. Australian Dental Journal, 43, 32-4. doi:10.1111/j.1834-7819.1998.tb00149.x

15. Lupi-Pegurier L., Muller M., Leforestier E., Bertrand M. F., Bolla M. (2003): In vitro action of Bordeaux red wine on the microhardness of human dental enamel. Archives of Oral Biology, 48, 141-145. doi:10.1016/S0003-9969(02) 00206-6

16. Willershausen B., Callaway A., Azrak B., Kloss C., SchultzDobrick B. (2009): Prolonged in vitro exposure to white wines enhances the erosive damage on human permanent teeth compared with red wines. Nutrition Research, 29, 558-567. doi:10.1016/j.nutres.2009.08.004

17. Mandel L. (2005): Dental erosion due to wine consumption. Journal of Americal Dental Association, 136, 71-75.

18. Mok T. B., McIntyre J., Hunt D. (2001): Dental erosion: In vitro model of wine assessor's erosion. Australian Dental Journal, 46, 263-268. doi:10.1111/j.1834-7819.2001. tb00290.x

19. Lolayekar N. V., Bhat V. S., Bhat S. S. (2007): Disinfection methods of extracted human teeth. Journal of Oral Health \& Community Dentistry, 1, 27-29.

20. López-Artiguez M., Cameán A. M., Repetto N. M. (1996): Determination of nine elements in sherry wine by inductively coupled plasma-atomic emision spectrometry. (1996): Journal of AOAC International, 79, 1191-1197.

21. Valeková M. (2012). Development of the methodology and analysis of the solutions after corrosion of ceramic biomaterials by ICP OES. Diploma Thesis, Alexander Dubček University of Trenčín.

22. Standard ČSN EN 1189, Quality of waters - Determination of phosphorus - Spectrophotomteric method with ammonium molybdate (in Czech). 
23. Jagessar R.C., Sooknanan L. (2011): Spectrophotometric determination of phosphates $\left(\mathrm{PO}_{4}^{3-}\right)$ anion in waste water from selected areas of coastal Guyana via the stannous chloride- molybdate calorimetric method. International Journal of Academic Research, 3, 98-107.

24. Boskey A. L. (2013): Biomaterials Science. $3^{\text {rd }}$ ed. Elsevier.

25. Park J., Lakes, R.S. (2007): Biomaterials, an introduction. $3^{\text {rd }}$ ed. Springer.

26. Dorozhkin S. (2002): A review on the dissolution models of calcium apatites. Progress in Crystal Growth and Characterization of Materials, 44(1), 45-61. doi:10.1016/ S0960-8974(02)00004-9
27. Dorozhkin S. V. (1997): Surface reactions of apatite dissolution, Journal of Colloid and Interface Science, 191, 489-497. doi:10.1006/jcis.1997.4942

28. Mika H., Bell L. C., Kruger B. J. (1976): The role of surface reactions in the dissolution of stoichiometric hydroxyapatite. Archives of Oral Biology, 21, 697. doi:10.1016/0003-9969(76)90145-X

29. Schaad P., Poumier F., Voegel J. C., Gramain Ph. (1997): Analysis of calcium hydroxyapatite dissolution in non-stoichiometric solutions, Colloids Surfaces A: Physicochemical and Engineering Aspects. 121, 217-228. doi:10.1016/S0927-7757(96)03977-5 